\title{
Educação e pós-modernidade: um olhar wittgensteiniano
}

\author{
Heloisa Helena Duval de Azevedo \\ Doutora em Filosofia pela PUC/RS e professora da UFPel \\ Neiva Afonso Oliveira \\ Doutora em Filosofia pela PUC/RS e professora da UFPel
}

\section{Resumo}

O presente trabalho argumenta, a partir do filósofo Ludwig Wittgenstein, que o jogo de linguagem pode contribuir na discussão sobre educação. Objetivamos introduzir a percepção da linguagem como elemento inerente ao ser humano para abordar a relação sobre educação. Diante desse panorama, o trabalho discute as possibilidades dos jogos de linguagem, onde há regras que podem ser ou não as mesmas entre um jogo e outro. Jogar não significa ganhar, ter razão ou a verdade. Podemos jogar pelo prazer de inventar um jogo ou para fazer valer argumentativamente nossa opinião. As considerações finais apontam para o desafio da pesquisa em educação, na disciplina de Paradigmas Filosóficos da Educação e provocam desafios na área da pesquisa filosóficoeducacional.

Palavras-chave: Pós-Modernidade; Educação; Linguagem.

\section{Resumé}

Le présent travail argumente, à partir du philosophe Ludwig Wittgenstein, que le jeu de langage peut contribuer dans la discussion sur éducation. Nous objectivons introduire la perception du langage comme élement inhérant à l'être humain pour aborder le rapport sur éducation. Devant ce panorama, le travail discute les possibilités des jeux de langage, où il y a des règles qui peuvent être ou ne pas être les mêmes entre un jeu et l'autre. Jouer ne signifie pas vaincre, avoir raison ou la vérité. Nous pouvons jouer par le plaisir d'inventer un jeu ou pour faire valoir argumentativement notre avis. Les considérations finales objectivent pour le défis de la recherche en éducation, dans la discipline de Paradigmes Philosophique de la Éducation et causent des défis dans le domaine de la recherche philosofique-éducationale.

Mots-clés: Postmodernité; Éducation; Langage. 


\section{Introdução}

$\mathrm{R}$

efletir sobre linguagem e educação nos incita a muitos pensamentos. Primeiramente, sobre a situação da educação nos os sujeitos da educação. Tema difícil de discorrer pela complexidade exigida no exercício da reflexão, as conexões existentes entre a filosofia da linguagem e educação podem servir de horizonte para pensarmos as relações pedagógicas fora de um modelo racionalista cartesiano ainda hegemônico. Nossa pretensão não é a de esgotar o assunto nesse momento, mas desejamos lançar um olhar para melhor entendimento do mesmo.

Para o exercício deste olhar, dividiremos nossa escrita em três momentos distintos, que, porém, se complementam. Em primeiro lugar, situaremos o aluno que vive e estuda nos dias atuais, bem como o professor contemporâneo. Que referências histórico-filosóficas estão presentes na relação professor-aluno? A que tipo de professor e aluno nos referimos? Em um segundo momento, usaremos o recurso que exige um olhar que retorna ao passado. Pois, como falar do que acontece hoje, sem o olhar que transita por nosso passado enquanto humanidade? Justamente em momentos de crise, nosso olhar volta-se para o que já vivemos. De que maneira chegamos até a Modernidade, e o que as viradas filosóficas, - consideremos três viradas - têm a ver com a educação? E Platão? Como falar sobre educação sem citá-lo? E Descartes? E Comte? Enfim, em terceiro lugar, escreveremos sobre a pós-modernidade, tema não consensual entre os teóricos das áreas da educação, da sociologia e/ou da filosofia. Podemos afirmar que há muitas tendências e também a dificuldade de se ter um conceito universal, ou uma fórmula - deveríamos buscá-los? - para expressar o que é pós-modernidade.

A fim de abordarmos as temáticas da linguagem e da educação, julgamos necessário transitar pelo movimento denominado condição pósmoderna ${ }^{1}$. Um tal procedimento propicia, no nosso entendimento, melhor compreensão das movimentações conceituais. Lembremos que o exercício

\footnotetext{
${ }^{1}$ É o francês Jean-François Lyotard (1924-1998) que utiliza o termo "condição pósmoderna" e entre os seus vários significados estaria o fim das metanarrativas.
} 
da universalidade é próprio do homem oriundo da tradição ocidental e a discussão sobre pós-modernidade não corrobora o modelo preponderante até então.

Ressaltamos, por fim, que a dificuldade está em teorizar sobre algo que estamos vivenciando neste momento. Esta tematização padece, portanto, da ausência de uma análise mais aprofundada e municiada pelo olhar histórico-crítico. Ao mesmo tempo, corre o risco que a ocasião epistemológica exige que corramos: “... que a balança de nossas análises penda menos para Parmênides... e um pouco mais para Heráclito" (Bassalobre, 2007). Sendo assim, o distanciamento de uma razão única e imutável em prol de um eterno devir torna-se um exercício complexo que, ao fim e ao cabo, parece ser o propósito do presente escrito.

\section{O aluno virtual}

Em sala de aula, nos deparamos com uma situação inusitada na relação professor-aluno. O aluno possui acesso a todo tipo de informação e, muitas vezes, não sabe como lidar com ela. O professor, por sua vez, é cria de uma tradição que exige o exercício da memória. Consideremos, aqui, memória como um conceito que significa evocação do passado, ou um exercício de reconstrução de lembranças; enfim, uma atividade temporal que pode ser individual, coletiva e científica, como veremos a seguir.

Imaginemos o mundo ao nosso redor como uma grande loja de conveniência, principalmente quando nos referimos à informação. A informação é oriunda da imprensa escrita (jornais, revistas, etc.), falada (rádio, televisão...), virtual (internet) e das ferramentas que esses veículos proporcionam. Aqui, optamos por enfatizar a televisão e a internet, pois, fornecem, de maneira rápida, elementos sobre assuntos que, muitas vezes, ultrapassam nosso conhecimento, ou melhor, nosso acesso ao conhecimento sob formas tradicionais, conforme tínhamos até um tempo atrás. Para ilustrar nosso argumento, basta lembrarmos que, ao ligar o aparelho de televisão ou o computador com acesso à internet, ficamos sabendo de situações como a da criança que estava se afogando e foi salva por um 
cachorro; ficamos a par de várias descobertas na medicina, como o uso de bacteriófagos em um país da antiga República Tcheca; de um professor agredido em sala de aula e da clonagem de animais motivada pela genética de excelência do exemplar matriz.

Com os exemplos citados acima, podemos olhar para o cotidiano e verificar que a informação é abundante e nos causa, em alguns momentos, certa confusão pela própria abastança. Também, a informação é uma espécie de memória que está relacionada a uma comunidade, seja ela de pesquisa ou não. Professor e aluno, portanto, têm acesso a um banco de dados via internet e através dela têm oportunidade de evocar o passado, ou seja, de restaurar uma memória científica.

Nossos alunos, segundo Donald Levine (apud Rodrigues, 2004, p. 13), professor de Sociologia da Universidade de Chicago, encontram-se diante da situação citada a seguir:

[...] cada vez mais a experiência chega em pequenos fragmentos. Vídeos despejam imagens; telespectadores pulam de canal em canal. As sinfonias tornam-se temas empacotados. A arte se transforma em colagens de ingredientes. Turistas compram cópias de partes de monumentos. As teorias estéticas dissolvem textos em amontoados de frases e palavras. Os computadores calculam em bytes, os políticos em pequenas e sólidas mordidas. A comida vem em rações processadas em microondas fornecida através de janelas em mostradores automatizados. Especialistas tratam pequenas partes de doenças, localizadas em corpos-mentes como um todo.

Essa é a realidade educacional quando nos referimos à informação. Em alguns lugares desse mundo, professores e alunos estudam como se estivessem numa loja de conveniência que fornece informações. Como avaliar se a informação acessada faz parte de uma memória científica confiável? Vivemos hoje o ápice de uma conjuntura orientada pela indústria cultural $?^{2}$

\footnotetext{
${ }^{2}$ É um termo cunhado por Theodor Adorno (1903-1969) e Max Horkheimer (1895-1973), membros da Escola de Frankfurt. Os autores criaram o conceito de indústria cultural para definir a conversão da cultura em mercadoria. $\mathrm{O}$ conceito não se refere aos veículos (televisão, jornais, rádio...), mas à utilização dessas tecnologias por parte da classe dominante. A produção cultural e intelectual passa a ser guiada pela possibilidade de consumo mercadológico.
} 
Nos bastidores das escolas e universidades, o que se escuta é a certeza de estarmos vivendo uma crise de paradigmas. O aluno de hoje não é como o aluno de alguns anos atrás, o professor não é mais respeitado e/ou reconhecido - e aqui falamos de reconhecimento com todo o significado que lhe emprestam as teorias filosóficas, como a hegeliana ${ }^{3}$, por exemplo. Constata-se que o estudante parece não exercitar a sua memória ou a memória coletiva. A internet, por seu turno, pode trazer o passado como memória científica e está disponível para quem possa acessá-la. O professor corre atrás de atualização, aperfeiçoamento e fórmulas para que o aluno aprenda a usar a sua memória, a memória coletiva e a memória científica. Nem sempre aquilo a que temos acesso é memória científica e, raramente, mais informação significa mais conhecimento. Em alguns instantes, chegamos a ansiar pela escola e pela universidade de 20 anos atrás. Naquele período, nossa experiência cultural parecia ser mais uniforme em função do modelo universal que herdamos dos ocidentais.

A miscelânea de informações que hoje recebemos parece dizer que exercitar a perspectiva teórica da contemporaneidade é aceitar tudo que é diferente do que conhecemos e, quem sabe, rechaçar o passado. Entretanto, exercitar a memória coletiva não é somente rememorar o passado como glorioso ou desgraçado. A memória coletiva situações que nos constituíram até o momento. Entretanto, a rapidez das nos auxilia em relação ao entendimento sobre quem somos e sobre as diversas informações pode nos fazer esquecer a coletividade e pode operar em favor da aceitação de uma epistemologia monoculturalista.

E nosso aluno? Nosso aluno vive a condição pós-moderna e tem acesso a uma memória através de informações nem sempre confiáveis. Sua herança educacional se encontra, entretanto, na modernidade. E mais: seu professor foi formado nos moldes da modernidade herdeira do método

\footnotetext{
${ }^{3}$ Georg W. F. Hegel retoma o modelo conceitual de uma disputa social entre os homens. Nas trilhas de análise da filosofia política hobbesiana e de N. Maquiavel. Já em Luta por reconhecimento: a gramática moral dos conflitos sociais, o filósofo alemão Axel Honneth, entre outras abordagens relativas às relações sociais, tematiza de forma atualizada à nossa conjuntura, aquilo que Hobbes e, posteriormente, Maquiavel denominariam luta pela autoconservação. O conceito filosófico reconhecimento, trabalhado por Honneth, na esteira da filosofia social de Hegel, associa-se a outros conceitos como amor, direito e solidariedade.
} 
cartesiano que inviabiliza, por exemplo, a reflexão voltada para o acontecimento da hibridação cultural. Nossas universidades estão fundadas na modernidade. E nossa memória científica? Bem, a memória científica está diretamente ligada à pesquisa de uma comunidade ou grupo de pesquisa. Nas universidades, podemos falar sobre o volume de informações que nos chegam e os critérios para selecioná-los. A excelência acadêmica é alcançada quando a produção científica atinge padrões estabelecidos por órgãos que a respaldam.

A estrutura educacional é igualmente herdeira da Modernidade, porém a situação apresentada em sala de aula, conforme afirmamos, é a de um aluno, que vive a condição pós-moderna. Temos um problema... Fazendo uso de uma figura ilustrativa, poderíamos recorrer ao exemplo de uma situação em que uma criança, alheia ao resultado da ação que pretendesse praticar, com um brinquedo de encaixe com figuras geométricas, tentasse interserir um quadrado no lugar de um círculo. Parece ser esta, também, a sensação de Gusdorf (2003, p. 55), quando se refere à situação de descompasso em que se encontram o ensino, a educação e a humanidade em geral:

Uma disciplina especializada que se fecha no soberbo isolamento de sua técnica separa-se de suas origens e de seus fins. Incapaz de se situar na totalidade do saber, na realidade humana, perde qualquer valor de cultura e torna-se um fator de alienação, como o atesta de modo evidente a crise atual de nossa civilização.

Por isso, regressaremos com nosso olhar para nossa própria história, nosso passado, a fim de tentar entender, não como a criança do brinquedo, mas como ser humano que pode lançar mão do seu tempo e de sua história passada para seu amadurecimento, ou seja, para a recuperação de sua memória. Essa é, certamente, uma via de busca de novas perspectivas para o exercício de educar e ser educado. 


\section{Nossa herança}

Em filosofia, falamos sobre três grandes viradas. A primeira, que compreende a Antigüidade e o Medievo e é denominada ontológica; a segunda, cuja abrangência é o período conhecido como Modernidade e que joga grande ênfase na consciência; finalmente, a terceira, que engloba a virada lingüística (linguistic turn) e é o período conhecido como contemporaneidade.

Em linhas gerais, o período que caracteriza a virada ontológica tem um modelo a ser seguido. Seja o da alma que estava no hiperurânio, o ato e a potência ou a imagem de Deus. Respeitando as diferenças entre os modelos, podemos afirmar que eles tentavam atingir um ideal de perfeição, fosse humano ou divino. Os autores do período formulavam teorias com vistas a atingir tal ideal. Um dos pensadores mais conhecidos e que corrobora nossa afirmação é Platão (428 a.C-347 a.C). Para Platão, mundo e linguagem correspondem. Nesse sentido, é somente considerado verdade aquilo que tem correspondência com o real. É só lembrar a discussão sobre “o ser é, e o não ser não é” de Parmênides (530 a.C-460 a.C) que nos lega a matriz da racionalidade orgulhosa da correspondência entre a verdade e o real e comprometida com a generalidade. Platão era um geômetra, que trabalhava com a matemática de uma maneira tal que sua pureza era apresentada na teoria das formas e no conceito de generalidade. Ou seja, a correspondência entre mundo e linguagem tinha de ser verdadeira e universal, havendo, portanto, uma única maneira de educar: a alma deveria relembrar o que vivera no hiperurânio. O corpo, então, deveria ser condicionado e aprender-se-ia matemática para somente, aí, chegar à filosofia. O modelo educacional platônico é ilustrado pelo mito da caverna: primeiramente, acreditamos, olhando as sombras, estar contemplando a verdade. E apenas após a saída da caverna quando a luz ofusca o olhar, é que podemos ver o sol, ou seja, a verdade. No Medievo ou Idade Média (século $\mathrm{V}$ até século $\mathrm{XV}$ ), a educação é exercida com a intenção de evangelizar, lembrando o ideal divino a ser seguido e tendo como meta o 
encontro com a unicidade de todas as coisas. Como produtor de cultura, o Medievo incorpora, intercala e resume o conhecimento conforme suas necessidades intelectivas que culminavam na busca de harmonização, em termos filosóficos, entre fé e razão.

A segunda virada tem como protagonista René Descartes (15961650). Descartes, como Platão, era um matemático. Viveu um período onde o conceito universal que envolve a palavra cultura estava ameaçado. Desde Platão, tem-se o exercício da universalidade como um ideal a ser seguido; e, no mundo conhecido, predominava o pensamento ocidental e sua cultura. Com o avanço das grandes navegações, a cultura ocidental conheceu outras culturas distintas. E agora? O que fazer? Como conciliar o diferente, o desconhecido com a tradição conhecida? A filosofia cartesiana conseguiu conciliar a situação. De tal forma que Deus é colocado em um outro patamar $^{4}$, não mais como um ser imutável, onisciente, mas sujeito à dúvida hiperbólica, e, quem sabe, também desejoso de que nos enganemos, apesar de "soberanamente bom” Em seu livro Meditações, Descartes apresenta o seu método utilizado até hoje nas ciências e nos oferece uma “... nova sensibilidade diante da realidade e da vida dando ênfase à ciência (Rodrigues, 2004, p. 35). O discurso continua universal, mas a novidade é o sujeito que pensa e, por isso, existe, é o Cogito ergo sum. O cartesianismo oferece a oportunidade do conhecimento ao sujeito pensante, consciente. Anteriormente, no período medieval, sujeito e substância mesclavam-se e não havia distinção conceitual clara entre eles. $\mathrm{O}$ método cartesiano destaca o sujeito cognoscente e inaugura um avanço nas ciências, principalmente naquelas que conhecemos como exatas. A universalidade é preservada... e a cultura da época também.

Posterior à consolidação da filosofia cartesiana e ao recorrente fortalecimento do método científico, Augusto Comte (1798-1857), francês como Descartes, vive a movimentação da burguesia e das massas na França. Sua teoria influencia o pensamento moderno e enfatiza ainda mais o exercício do pensamento científico. A filosofia positiva comtiana divide a

\footnotetext{
${ }^{4}$ Nossa intenção não é aprofundar a temática sobre Deus na obra de Descartes.
} 
história da humanidade em três estados: o teológico, o metafísico e o positivo, este último guiado pelo pensamento científico. $\mathrm{O}$ estado teológico compreende o período onde recorremos ao sobrenatural para explicar o real; o metafísico apresenta uma razão desvinculada da realidade concreta e objetiva utilizando conceitos muito abstratos como potência, essência e ato; o estado positivo, guiado pelo pensamento científico, ancora-se na experiência real e nos dados objetivos. A humanidade deveria guiar-se pelo estado positivo, tendo o amor por princípio, a ordem por base e o progresso por fim. A tarefa de guiar os homens era dos proprietários, cientistas e responsáveis pela cultura. O povo deveria trabalhar ordeiramente na produção. Sucessor imediato de Condorcet, conforme se autodenomina, Comte elabora uma teoria sobre o desenvolvimento da humanidade, no qual as descobertas e invenções da ciência e da tecnologia desempenham papel preponderante, fazendo o homem progredir em direção a um período em que a organização social e política seria resultado das luzes da razão.

O modelo desse período é baseado no otimismo da razão e da ciência contrapondo-se à tradição e à religião. O ser humano deve ter sua educação voltada para os bens supremos que são, agora, a razão e a ciência. E, para que isto aconteça, segundo Comte, a educação deve ser destinada a todos. Alguns comandarão, por isso, uma educação de elite; outros produzirão uma educação que proporcione um mínimo de condições para que participem do estado positivo. O modelo cultural eurocêntrico permanece. Nas palavras de Mühl (2008, p. 210-1):

A educação, como campo das ciências humanas, também necessita ser compreendida e desenvolvida com base em critérios científicos. Ela cumpre o papel de levar cada ser humano a viver o estado positivo [...] A ordem positiva de Comte representa o primado da dominação do conhecimento econômico e político sobre a humanidade. O conceito social positivista, por intermédio de uma visão monológica e funcional, encobre as estruturas de dominação do Estado [...] A ordem existente representa a positiva, que atingiu seu mais alto grau de desenvolvimento e se mantém inalterada pela vigência de leis inabaláveis e eternas.

À linguagem está relacionada a terceira virada. No período em questão, século XX, paira um sentimento de desilusão em relação à 
metafísica, à razão e à ciência, as quais passam a ser subjugadas pelo que costumamos denominar filosofia da mente.

Segundo Jean-François Lyotard, "A crise do saber científico não provém de uma proliferação fortuita das ciências que seria ela mesma o efeito do progresso das técnicas e da expansão do capitalismo. Ela procede da erosão interna do princípio de legitimação do saber" (2008, p. 71). A busca da verdade com suas raízes gregas está sendo questionada. Utilizando a memória, podemos dizer que a exaltação da razão não respondeu à pergunta sobre o que é a verdade, tampouco tocou nos grandes anseios humanos. O modelo cultural vigente até então não responde ao cotidiano, ao entorno e à vida.

A virada lingüística surge num momento de grandes questionamentos e em relação à mesma não podemos deixar de mencionar Ludwig Wittgenstein (1889-1951). Pois ele se movimenta dentro da tradição moderna resguardando a universalidade do saber científico no Tractatus Logico-philosophicus. Quanto ao termo virada lingüística, dizemos que é usado por muitos intelectuais contemporâneos a Wittgenstein e só aparece oficialmente em 1966 numa coletânea de textos sobre linguagem, de Richard Rorty (1931-2007), intitulada The Linguistic Turn. Wittgenstein é figura chave, pois se, de um lado, resguarda a tradição moderna no Tractatus Logico-philosophicus, onde aborda as questões da linguagem e seus limites, de outra parte, sua atenção não está voltada para a universalidade nas Investigações Filosóficas, obra póstuma.

Na primeira obra, o filósofo austríaco nos dá algumas pistas sobre a mudança, a princípio radical, porque, segundo alguns, ele pretenderia acabar com a ética, a filosofia e a religião. Dizemos a princípio radical, porque através de uma leitura mais atenta, encontramos um aforismo afirmando que os problemas da vida não são nem sequer tocados pela ciência e, em outro, afirma que a ética e a estética são uma só. Nesse sentido, as inquietações de Wittgenstein aparecem soltas entre aforismos sobre lógica, verdade e sobre como se correspondem mundo e linguagem. Só entendemos essa mudança ao lermos seus diários e ao presenciar o que acontece ao nosso redor. 
Atrevemo-nos a dizer que ele é um homem de seu tempo que antevê o que Lyotard chama de condição pós-moderna.

\section{Enfim, a pós-modernidade}

Para falarmos sobre pós-modernidade, precisamos relembrar memórias recentes que tratam da assim denominada condição pós-moderna. A chamada pós-modernidade inicia sua trajetória como um exercício na área da arquitetura, exercício esse que recebe a denominação de colagem. Em um projeto, diversas tendências e estilos deveriam ser sobrepostos. Mas, em que ponto podemos relacionar arquitetura e educação? Um movimento iniciado na arquitetura encontra fundamentação filosófica com vistas às análises que podemos fazer em relação, por exemplo, aos conceitos saber e poder. JeanFrançois Lyotard em seu livro A Condição Pós-Moderna apresenta para as ciências humanas uma característica daquilo que vivemos na contemporaneidade: a desencarnação do saber e a ausência do poder pessoal. Segundo Barbosa (2008, p. xiii): “O pós-modernismo, enquanto condição da cultura nesta era caracteriza-se exatamente pela incredulidade perante o metadiscurso filosófico-metafísico, com suas pretensões atemporais e universalizantes".

O discurso moderno que eleva a razão e a ciência vislumbra um ser humano que, sob a égide das mesmas, atinge sua maturidade. $\mathrm{O}$ que a história da humanidade apresentou, e sobre o que Wittgenstein nos fornece pistas, é o fato de que mesmo com todo avanço tecnológico e progresso da razão humana, nossa vida, nossos problemas do cotidiano não são nem tangenciados. Lyotard e outros pensadores que teorizam sobre a pósmodernidade afirmam que vivemos um período de desconstrução do cotidiano, do modelo cartesiano, das metanarrativas, da cultura e das utopias. A condição pós-moderna emana de movimentos contraditórios e dos exageros econômicos da modernidade.

$\mathrm{O}$ autor de A Condição Pós-moderna se inspira na linguagem, mais especificamente no jogo de linguagem de Wittgenstein para propor novos vínculos. Estes vínculos são feitos como se fossem lances de linguagem. 
Eis: " $1^{\circ}$, a regra não pode se legitimar nela mesma, mas a linguagem é constituída de regras; $2^{\circ}$, sem regras, não há jogo, e $3^{\circ}$, todo enunciado deve ser considerado como um lance num jogo (Lyotard, 2008, p. 15-18)".

Inspirados em Lyotard (2008), podemos dizer que seria impossível submeter todos os discursos, ou jogos de linguagem à autoridade de um metadiscurso. E isso vale para os discursos proferidos na educação. Esse pretenso movimento de submissão dos diversos discursos ou jogos de linguagem à universalidade de uma dada teoria aponta para a dificuldade que vivemos na sala de aula onde existe a confusão de que a condição pósmoderna seja uma regra que derruba todas as anteriores $\mathrm{E}$ de que os argumentos válidos na Modernidade devam ser colocados na lixeira e nossa memória também seja descartada. Também não se pode pretender indicar o oposto, apontando para a condição pós-moderna como se esta não fosse algo sério e pudesse ser considerada, então, um modismo passageiro. Uma tal posição a deixaria relegada a um canto escondido da memória coletiva e não afetaria nossas vidas.

Com o intuito de clarear o tema, utilizaremos o recurso da memória para entender o que é o jogo de linguagem. Em Investigações Filosóficas, Wittgenstein (1996, p. 26-27), no aforismo 23, escreve sobre o que é um jogo de linguagem:

A expressão "jogo de linguagem" deve salientar aqui que falar uma língua é parte de uma atividade ou de forma de vida. Tenha presente a variedade de jogos de linguagem nos seguintes exemplos, e em outros:

Ordenar, e agir segundo as ordens-

Descrever um objeto pela aparência ou pelas medidas-

Produzir um objeto de acordo com uma descrição (desenho)-

Relatar um acontecimento-

Fazer suposições sobre o acontecimento-

Levantar uma hipótese e examiná-la-

Apresentar os resultados de um experimento por meio de tabelas e diagramas-

Inventar uma história; e ler-

Representar teatro-

Cantar cantiga de roda-

Adivinhar enigmas-

Fazer uma anedota; contar-

Resolver uma tarefa de cálculo aplicado-

Traduzir de uma língua para outra- 
Pedir, agradecer, praguejar, cumprimentar, rezar.

Relembramos o que Wittgenstein considera jogo de linguagem para entender o que Lyotard propõe. Partindo do jogo de linguagem, nossas relações não são mais vistas como essencialistas, voltadas para consciência ou histórico-críticas. Elas são jogos onde há regras que podem ser ou não as mesmas entre um jogo e outro. Jogar não significa ganhar, ter razão ou a verdade. Podemos jogar pelo prazer de inventar um jogo ou para fazer valer argumentativamente minha opinião. Essa compreensão e procedimentos nos levam ao educador que se encontra mergulhado no jogo da pesquisa. A competência do educador, segundo Lyotard, é requerida unicamente sobre a posição dos enunciados. Podemos dizer ainda: aqueles que detêm mais informações em um banco de dados em nossa memória científica, são os que detêm o poder. Isso nos faz entender as exigências para com os alunos e principalmente para com professores pesquisadores. Atualmente, os cursos de nível superior, melhor dizendo, os cursos de especialização e em nível de mestrado e doutorado, são considerados de excelência conforme a produção científica dos alunos e, principalmente, dos professores dos mesmos. Dessa maneira, a memória científica é evocada a cada instante em todo o mundo. $\mathrm{E}$ a tradição moderna persiste, pois quem dita as regras não são os países da América Latina. A tradição se mantém, uma vez que vivemos a adequação do saber. A memória científica da América Latina é recente e está alcançando os níveis de excelência exigidos pela comunidade internacional. Partindo daí, podemos entender a relação entre educação e linguagem. Considerando a herança helênica, dizemos que o exercício do logos, legado da Grécia Antiga, não reconhece o que é diferente. E, o pensamento moderno, sucessor da tradição grega, parte de um eu sou/eu penso dirigindose para um movimento, o qual conhecemos como eurocentrismo. Descartes, na modernidade, salvaguarda a tradição da universalidade e a cultura é preservada. Julgando a influência da obra Investigações Filosóficas de Wittgenstein no livro de Jean-François Lyotard A Condição Pós-moderna, atrevemo-nos a dizer que o jogo de linguagem proposto por Wittgenstein e 
adotado por Jean-François Lyotard inspira, por meio da linguagem, aspectos da contemporaneidade sob a ótica do que chamamos de pós-modernidade.

Wittgenstein (s.d., p.19), em Cultura e Valor, diz que o livro é para os que compartilham do espírito da sua escrita e que ele não segue o espírito da corrente mais importante da civilização americana e européia. Estas anotações são posteriores às da obra póstuma Investigações Filosóficas, e apontam para um entendimento próximo da discussão contemporânea atualidade. Segundo Wittgenstein (s.d., p. 20), em Cultura e Valor:

Uma cultura é como uma grande organização que atribui a cada um dos seus membros um lugar em que ele pode trabalhar no espírito do conjunto; e é perfeitamente justo que o seu poder seja medido pela contribuição que consegue dar ao todo. Numa época sem cultura, por outro lado, as forças tornam-se fragmentárias e o poder do indivíduo consome-se na tentativa de vencer forças opostas e resistências ao atrito; tal poder não é visível na distância que percorre, mas talvez unicamente no calor por ele produzido ao vencer o atrito. Mas a energia continua a ser energia, e embora o espetáculo que a nossa época nos proporciona não seja o da formação de uma grande obra cultural, com os melhores homens a contribuir para o fim grandioso, mas o espetáculo mais impressivo de uma multidão cujos melhores membros trabalham com vistas à realização de objectivos puramente pessoais, mesmo assim não nos devemos esquecer de que o espetáculo não é o que interessa. Compreendo, por isso, que o desaparecimento de uma cultura não significa o desaparecimento do valor humano, mas apenas o desaparecimento de expressar este valor.

As manifestações culturais são encontradas na música, nas artes, na arquitetura, na indústria (hoje, na indústria da moda) e em outras tantas formas de expressão. Para Wittgenstein, seja em época sem cultura ou de cultura elevada, o indivíduo, de uma forma ou de outra, consegue se expressar. Podemos não compreender sua linguagem imediatamente ou julgar depreciativamente. Mas, ainda sim, a expressão cultural de um período e/ou de um grupo tem valor pelo fato de conseguir expressão, mesmo que não seja de acordo com os padrões conhecidos pela civilização americana ou européia. Se essa expressão perde importância, não há qualquer tipo de modificação. Mas, se ela se destaca, temos um novo jogo de linguagem. E se há um novo jogo, há mudança conceitual e, com essas mudanças, mudam os significados. 
Dizendo de outro modo, a relação mundo e linguagem de Investigações Filosóficas traz a linguagem para o cotidiano. Ao contrário do Tractatus, Investigações Filosóficas coloca, como centro da linguagem, o mundo da comunidade lingüística que interpreta. É por meio do jogo da linguagem que seus membros entendem a si mesmos, aos outros e ao mundo Os jogos de linguagem geram múltiplas formas de convivência. O jogo é uma atividade, e a significação passa a ser a capacidade de seguir uma regra e de aprender a jogar cada jogo.

\section{Considerações finais}

Sendo assim, não temos a pretensão de finalizar o assunto. Consideremos que até certo momento da contemporaneidade, conseguimos entender, teorizar, sugerir e vivenciar o que nos é apresentado. Quando entra em cena a discussão sobre linguagem e educação, encontramos uma primeira dificuldade. Como definir, utilizando os moldes da modernidade, algo que se afasta e critica a mesma? Aí, se encontra a dificuldade atual. Nos perguntamos sobre o modo como em um mundo marcado pela globalização, com tradições religiosas, educacionais e culturais distintas, podemos conviver com valores, religiões, culturas que não são mais universais?

Em se tratando da educação, recorremos a Barbosa (2008, p.xii) quando este sintetiza primorosamente o que o professor está vivenciando nos dias atuais:

Nessas circunstâncias, a universidade, o ensino, e a pesquisa adquirem novas dimensões: formam-se pesquisadores ou profissionais, investe-se na pesquisa e na sua infra-estrutura não mais com o objetivo de preparar os indivíduos eventualmente aptos a levar a nação à sua "verdade", mas sim formar competências capazes de saturar as funções necessárias ao bom desempenho da dinâmica institucional.

Professor e aluno estão diante da Deusa Hécate, deusa tríplice lunar, que guarda as encruzilhadas. Estamos parados diante do cruzamento e temos de escolher para onde nos dirigir. Trazemos nossa memória, seja ela a individual, a coletiva ou a científica para decidir qual o caminho a seguir. 
Bem, este é o panorama que se apresenta diante de nós. É difícil seguir um modelo como se fosse universal e absolutamente verdadeiro. E essa é a nossa dificuldade. Desde Platão, tem-se a tendência à generalização e à busca da verdade. A memória na Antigüidade era algo sobrenatural, tinha sua representação na deusa Mnemosyne que dava o dom, aos poetas e adivinhos, de relembrar o passado e trazê-lo para a coletividade. Sentimonos como mergulhadores fazendo seu exercício de mergulho numa grande profundidade e, ao retornar à superfície, vemos a mudança ocasionada por um Tsunami. Lá embaixo, não sentimos nem percebemos nada diferente. Porém, grandes mudanças aconteceram na superfície; com o exercício da memória de outros, podemos entender a transformação ocorrida.

Diz-se que velhas formas não são aconselhadas pela maioria dos simpatizantes do movimento pós-moderno. No entanto, melhor considerar ponto a favor dos mesmos o desafio lançado pelo movimento de reconhecimento de diferentes memórias, de culturas distintas e de apontar um olhar possível, pela via sempre disponível da filosofia da educação, uma saída da estagnação enquanto profissionais da educação. Uma tal tarefa da filosofia da educação pode ser o elemento que nos auxilia no discernimento e na compreensão de momentos filosóficos diversos.

$\mathrm{Na}$ reflexão sobre linguagem e educação, regras prontas para ensinar/aprender ou fórmulas para jogar não devem ser esperadas. O exercício do jogo de linguagem proposto por Wittgenstein nos propicia compreender a educação como prática social, como fenômeno da história social e política dos homens, e principalmente, como jogo de participantes de vários mundos Trata-se, podemos afirmar, de um jogo inspirado em Wittgenstein e um exercício onde a ajuda da deusa Mnemosyne, deusa grega e titã da memória, pode contribuir para pensarmos e agirmos em uma convivência no ambiente educacional. 


\section{Referências}

BARBOSA, Wilmar do Valle. Tempos Pós-modernos. In: Jean-François Lyotard. A Condição Pós-moderna. Rio de Janeiro: José Olympo Editora, 2008.

BASSALOBRE, Janete Netto. A educação em tempos de crise paradigmática. Cadernos de Educação, Pelotas, n.29, p.173-189, jul./dez. 2007.

GUSDORF, Georges. Professores para quêe? São Paulo: Martins Fontes, 2003.

LYOTARD, Jean-François. A Condição Pós-moderna. Rio de Janeiro: José Olympo Editora, 2008.

MÜHL, Eldon. A crise da modernidade inacabada e os desafios da educação contemporânea. In: Cláudio A. Dalbosco, Edison. A. Casagranda, Eldon H. Mühl (Orgs.). Filosofia e pedagogia: aspectos históricos e temáticos. Campinas: Autores Associados, 2008, p. 109-140.

RODRIGUES, Alberto Tosi. Sociologia da Educação. Rio de Janeiro: DP\&A, 2004.

WITTGENSTEIN, Ludwig. Cultura e Valor. Lisboa: Edições 70, s.d.

WITTGENSTEIN, Ludwig. Investigações Filosóficas. 2. ed. Petrópolis: Vozes, 1996. 